\begin{tabular}{|c|c|}
\hline Citation & $\begin{array}{l}\text { Martin, D.E., Nakagawa, T.A. (2015), } \\
\text { Pediatric Deceased Donation - A Report of the Transplantation Society } \\
\text { Meeting in Geneva } \\
\text { Transplantation, 99(7), } 1403-1409 .\end{array}$ \\
\hline Archived version & Final publisher's version / PDF \\
\hline Published version & http://dx.doi.org/10.1097/TP. 0000000000000758 \\
\hline Journal homepage & http://journals.Iww.com/transplantjournal/pages/default.aspx \\
\hline Author contact & $\begin{array}{l}\text { Fabienne.dobbels@med.kuleuven.be } \\
\text { + } 32(0) 16373402\end{array}$ \\
\hline IR & https://lirias.kuleuven.be/cv?u=U0015258 \\
\hline
\end{tabular}

(article begins on next page) 


\section{Pediatric Deceased Donation-A Report of the Transplantation Society Meeting in Geneva}

Dominique E. Martin, MBBS, PhD, ${ }^{1}$ Thomas A. Nakagawa, MD, ${ }^{2}$ Marion J. Siebelink, PhD, ${ }^{3}$ Katrina A. Bramstedt, PhD, ${ }^{4}$ Joe Brierley, MBChB, FRCPCH, ${ }^{5}$ Fabienne Dobbels, PhD, ${ }^{6}$ James R. Rodrigue, PhD, ${ }^{7}$ Minnie Sarwal, MD, PhD, ${ }^{8}$ Ron Shapiro, MD, ${ }^{9}$ Beatriz Dominguez-Gil, MD, PhD, ${ }^{10}$ Gabriel Danovitch, MD, ${ }^{11}$ Stuart C. Sweet, MD, PhD, ${ }^{12}$ Richard S. Trompeter, FRCP, FRCPCH, ${ }^{13}$ Farhat Moazam, MD, PhD, ${ }^{14}$ Michael A. Bos, MSoc, ${ }^{15}$ and Francis L. Delmonico, MD $^{16}$

The Ethics Committee of The Transplantation Society convened a meeting on pediatric deceased donation of organs in Geneva, Switzerland, on March 21 to 22, 2014. Thirty-four participants from Africa, Asia, the Middle East, Oceania, Europe, and North and South America explored the practical and ethical issues pertaining to pediatric deceased donation and developed recommendations for policy and practice. Their expertise was inclusive of pediatric intensive care, internal medicine, and surgery, nursing, ethics, organ donation and procurement, psychology, law, and sociology. The report of the meeting advocates the routine provision of opportunities for deceased donation by pediatric patients and conveys an international call for the development of evidencebased resources needed to inform provision of best practice care in deceased donation for neonates and children.

(Transplantation 2015;99: 1403-1409)

\section{OVERVIEW OF THE MEETING}

An international meeting was convened by the Ethics Committee of The Transplantation Society in Geneva, Switzerland, on March 21 and 22, 2014, to explore the practical and ethical issues pertaining to pediatric deceased donation of organs (hereafter, pediatric donation). There were 34 participants from Africa, Asia, the Middle East, Oceania, Europe, and North and South America, with expertise inclusive of pediatric intensive care, internal medicine, and surgery, nursing, ethics, organ donation and procurement,

Received 1 July 2014. Revision requested 10 November 2014.

Accepted 21 December 2014.

${ }^{1}$ Centre for Health Equity, School of Population and Global Health, the University of Melbourne, Melbourne, VIC, Australia.

${ }^{2}$ Department of Anesthesiology and Pediatrics, Wake Forest School of Medicine, Winston-Salem, NC.

${ }^{3}$ University Medical Center Groningen, University of Groningen, Groningen, the Netherlands.

${ }^{4}$ Faculty of Health Sciences and Medicine, Bond University, Robina, QLD, Australia.

${ }^{5}$ Great Ormond Street Hospital for Sick Children, London, United Kingdom.

${ }^{6}$ Department of Public Health and Primary Care, University of Leuven (KU Leuven), Leuven, Belgium.

${ }^{7}$ Beth Israel Deaconess Medical Centre, Boston, MA.

8 Division of Transplant Surgery, University of California San Francisco, San Francisco, CA.

${ }^{9}$ Thomas E. Starzl Transplantation Institute, University of Pittsburgh, Pittsburgh, PA.

${ }^{10}$ Organización Nacional de Trasplantes, Madrid, Spain.

11 David Geffen School of Medicine, University of California Los Angeles, Los Angeles, CA.

${ }^{12}$ Department of Pediatrics, Washington University, St. Louis, MO.

${ }^{13}$ UCL Centre for Nephrology, Royal Free Campus, London, United Kingdom. psychology, law, and sociology (Table 1). Participants were selected by a multidisciplinary steering committee, and representation was sought from regional professional societies of transplantation.

The intent of the meeting was to provide ethically informed practical recommendations for health professionals and policy makers seeking to establish or improve existing pediatric organ donation programs globally, and to identify neglected opportunities for research in this field. Four work groups were electronically convened prior to the meeting, to address the following topics that were subsequently presented and reviewed in breakout and plenary sessions in Geneva:

\footnotetext{
${ }^{14}$ Center of Biomedical Ethics and Culture, SIUT, Karachi, Pakistan.

${ }^{15}$ Ethics Committee, The Transplantation Society, Montreal, QC, Canada.

${ }^{16}$ Massachusetts General Hospital, Harvard Medical School, Boston, MA.
}

The Transplantation Society Meeting in Geneva on Pediatric Deceased Donation was funded by the Transplantation Society and an educational grant from Teva. Teva had no role in the design and conduct of the meeting, nor in the preparation, review, or approval of this manuscript.

The authors declare no conflicts of interest.

D.M. wrote the initial draft of this article, and was responsible for subsequent revisions, with substantial assistance from T.N. F.L.D. participated in the design and drafting of the article. T.N., M.S., K.B., J.B., F.D., J.R., M.S., R.S. also assisted with revisions to the article. B.D.G. contributed writing and assisted with important structural revisions. G.D., S.S., R.T., F.M., and M.B. contributed to the writing and content to revisions of the article.

Correspondence: Dominique Martin, Level 4, 207 Bouverie Street, University of Melbourne, 3010, Australia. (dominique.martin@unimelb.edu.au).

Copyright @ 2015 Wolters Kluwer Health, Inc. All rights reserved.

ISSN: 0041-1337/15/9907-1403

DOl: $10.1097 /$ TP.0000000000000758 
TABLE 1.

List of pediatric donor meeting participants

\begin{tabular}{|c|c|c|}
\hline Barbari & Antoine & Representative MESOT, Lebanon \\
\hline Bennett & Renee & Representative ITNS, United States \\
\hline Bos & Michael & $\begin{array}{l}\text { Chair, TTS Ethics Committee, the } \\
\text { Netherlands }\end{array}$ \\
\hline Bouësseau & Marie-Charlotte & WHO, Switzerland \\
\hline Bramstedt & Katrina & Bond University, Australia \\
\hline Brierley & Joe & $\begin{array}{l}\text { Great Ormond Street Hospital for Sick } \\
\text { Children, United Kingdom }\end{array}$ \\
\hline Danovitch & Gabriel & UCLA, United States \\
\hline Delmonico & Francis & President, TTS, Canada \\
\hline Dhawan & Anil & Representative ILTS, United Kingdom \\
\hline Dobbels & Fabienne & University of Leuven (KU Leuven), Belgium \\
\hline Domínguez -Gil & Beatriz & Representative ONT, Spain \\
\hline $\mathrm{Ha}$ & Jongwon & Representative AST, South Korea \\
\hline Harmon & William & Children's Hospital Boston, United States \\
\hline Joseph & Mathew $^{a}$ & Christian Medical College Vellore, India \\
\hline Langer & Robert & Semmelweis Institute, Hungary \\
\hline Lewis & Penney & King's College London, United Kingdom \\
\hline Martin & Dominique & The University of Melbourne, Australia \\
\hline McCulloch & Mignon & University of Cape Town, South Africa \\
\hline McDiarmid & Sue $^{a}$ & UCLA, United States \\
\hline Moazam & Farhat & $\begin{array}{l}\text { Center for Biomedical Ethics and Culture, } \\
\text { SIUT, Pakistan }\end{array}$ \\
\hline Myrick & Craig & Representative NATCO, United States \\
\hline Nakagawa & Thomas & $\begin{array}{l}\text { Wake Forest School of Medicine, } \\
\text { United States }\end{array}$ \\
\hline Nino-Murcia & Alejandro & Representative STALYC, Colombia \\
\hline Noël & Luc & WHO, Switzerland \\
\hline O'Connell & Philip & President-Elect TTS, Australia \\
\hline Rodrigue & James & $\begin{array}{l}\text { Beth Israel Deaconess Medical Centre, } \\
\text { United States }\end{array}$ \\
\hline Sarwal & Minnie & $\begin{array}{l}\text { University of California San Francisco, } \\
\text { United States }\end{array}$ \\
\hline Schotsmans & $\mathrm{Paul}^{a}$ & Representative ESOT, Belgium \\
\hline Shapiro & Ron & Children's Hospital Pittsburgh, United States \\
\hline Siebelink & Marion & $\begin{array}{l}\text { University Medical Centre Groningen, the } \\
\text { Netherlands }\end{array}$ \\
\hline Siminoff & Laura & Temple University, United States \\
\hline Sweet & Stuart & Representative ISHLT, United States \\
\hline Trompeter & Richard & Representative IPTA, United Kingdom \\
\hline Weimar & Willem & Representative ELPAT, the Netherlands \\
\hline
\end{tabular}

${ }^{a}$ These individuals participated in preparatory work for the meeting but were unable to attend in person.

- Donor recognition and policy in the Pediatric Intensive Care Unit (PICU)

- Ethical Challenges in End-of-Life Care

- Family Decision Making

- Allocation of Pediatric Donor Organs

A further plenary session occurred to discuss the issue of death determination in children. In this report, we review the common themes of discussion and key recommendations that emerged from this meeting.

\section{THE IMPORTANCE OF PEDIATRIC DONATION}

Organizations, such as the American Academy of Pediatrics, encourage physician education and participation in pediatric donation, collaboration with organ procurement organizations, and advocate equity in donation and transplantation. ${ }^{1}$ Nevertheless, pediatric donation remains a neglected subject of research and public commentary internationally. ${ }^{2}$ This contributes to a lack of awareness among policy makers, health professionals, and the public regarding opportunities to establish or improve donation programs.

Optimizing donation and utilization of pediatric organs and the experience of donor families and professional staff involved in their care are key components of efforts to meet increasing needs for transplantation. Thousands of children and adults benefit from transplants using deceased donor organs annually. ${ }^{3}$ However, limitations inherent in sizematching organs to pediatric recipients exacerbate difficulties in providing transplants for children. More than 150 children die annually while awaiting organ transplantation in the United States and Europe., ${ }^{2,4}$ Although deaths may be declining, more children are removed from waiting lists because their condition deteriorates, and they become ineligible for transplantation. ${ }^{4}$ In some countries, lack of pediatric deceased donation programs means that children in need of transplantation, especially hearts, lungs, and livers, will die unless they are able to travel abroad and receive compassionate access to foreign transplant programs.

Pediatric donation represents a small but invaluable portion of the deceased donor pool, comprising roughly $6 \%$ of deceased donors in the United States ${ }^{6}$ and $3 \%$ in Australia, the United Kingdom, ${ }^{8}$ Spain, ${ }^{9}$ and Eurotransplant countries. Conversely, children comprise approximately $1.5 \%$ of the waiting list for transplantation in the United States ${ }^{11}$ and in Eurotransplant countries, ${ }^{10} 2 \%$ in the United Kingdom, ${ }^{12}$ $3 \%$ in Australia, ${ }^{13}$ and $6 \%$ in Spain. ${ }^{9}$ (We note there is international variation in definition of pediatric donors according to age: in the United States and the United Kingdom, pediatric donors are those in the category of 0 to 17 years; in Australia and Spain, published data groups pediatric donors from 0 to 14 years, and in Eurotransplant from 0 to 15 years. ${ }^{10}$ For the purpose of organ allocation, definition of pediatric recipients according to age also varies between and within countries and according to organ type. ${ }^{10}$ )

Studies evaluating the potential of neonatal and pediatric donation are scarce. ${ }^{14-18}$ Nevertheless, the proportion of PICU deaths potentially suitable for organ donation in countries such as Spain and the Netherlands is estimated at approximately $11 \% .^{9,14}$ The falling rates of donation after brain death and rising rates of donation after circulatory death (DCD) in the United States ${ }^{3}$ and some Western European countries $^{9,14}$ indicate an evolving pattern of donor potential in general terms, and in pediatrics in particular. The incidence of brain death in the pediatric population is fortunately declining as a result of general safety measures and advancements in neurocritical care. This has been observed in a recent study in Spain (from 25 pediatric brain death cases per million population in 2000 to less than 10 in 2011). ${ }^{9}$

\section{DONATION IN END-OF-LIFE CARE}

Withdrawal of life-sustaining medical therapies should be viewed as a process, rather than an event. Opportunities for donation are often lost during end-of-life care, especially when withdrawal of medical therapies takes place without early notification of "key donation persons" (KDPs) to allow engagement with the family or health care team and to 
enable timely evaluation of possible donors. ${ }^{18}$ Noting there is considerable international variation in terminology and role descriptions of professionals engaged in organ recovery activities, the term "key donation person" is used throughout this report to refer to an organ donation specialist or equivalent: the professional with primary responsibility for donation in a particular setting. The KDP should be included in discussions about end-of-life care and donation with other individuals responsible for provision of end-of-life care. An institutional culture where end-of-life care is inclusive of opportunities for donation supports early referral and preserves the option of donation for patients and families.

Forensic cases involving the medical examiner or coroner may also impair opportunities for donation when request for donation is denied by these authorities. ${ }^{18}$ Early involvement and education of the medical examiner or coroner is essential to ensure evidence is not altered or lost during the donation process.

Despite the well-recognized value of saving and improving lives through organ transplantation, families and health care professionals may perceive elements of the donation process as ethically challenging during end-of-life care. These ethical challenges can occur during patient management, and especially in the context of DCD. ${ }^{19,20}$ Unfounded parental hopes of recovery and survival, and fears that cessation of futile interventions may result in withdrawal of care for their child may underpin reluctance to consider donation. ${ }^{19,21}$ Concerns about harming potential donors or their families through discussion of donation, use of interventions to preserve donation opportunities, or recovery of organs after death is declared may discourage health professionals from enabling donation opportunities. ${ }^{20}$ These apparent conflicts between the interests of a potential donor and their family and the benefits anticipated from donation may result from inadequate communication between staff and family. Furthermore, lack of appropriate education about donation and end-of-life care, and lack of experience among staff for whom pediatric donation is usually a rare event can result in poor understanding and implementation of donation protocols and procedures, ultimately affecting the donation process.

When providing end-of-life care, the child's best interests must be paramount, with due consideration of the principles of beneficence (promoting welfare) and nonmaleficence (minimizing harm). Such interests include previously expressed preferences of the child regarding donation when these are known. ${ }^{22}$ The interests of children, like those of adults, should be recognized as socially embedded, with consideration for the interests of families where relevant. Potential harms to the interests of the child and family may include prolongation of the dying process, use of futile interventions, and delayed decision making that may preclude the option for donation.

Provision of optimal care at the end of life is an ethical duty of health care professionals caring for dying patients. This encompasses a duty not to offer or implement futile interventions and to withdraw interventions when they become futile. Families should be assured that the cessation or withdrawal of interventions when deemed futile does not mean withdrawal of care for the child. End-of-life care must include the management of the child's symptoms, including pain and suffering, as well as provision of emotional and spiritual support to the child and family. ${ }^{19,23}$ It should be an expectation that parents and family are offered the option of being present during end-of-life care and during the determination of death. ${ }^{19,23}$

\section{SYSTEMATIC IDENTIFICATION AND ROUTINE REFERRAL OF POTENTIAL DONORS}

Organs transplanted from pediatric donors provide excellent outcomes for many recipients, yet multiple factors contribute to missed or neglected opportunities for pediatric donation. ${ }^{3,14-18}$ Evidence available indicates that rates of donor identification within PICUs vary considerably. ${ }^{14,18}$ In a national study conducted in the Netherlands, rates ranged from $60 \%$ to $95 \%$ across different PICUs. ${ }^{14}$ In a national U.S. study, hospitals with a level 1 trauma program and/or a pediatric critical care fellowship had higher donation rates. ${ }^{18}$ Early assessment and routine referral of possible donors to a KDP representing the relevant organ procurement organization or equivalent should help to prevent missed opportunities for donation, as evidenced in adult donation programs. ${ }^{24,25}$ Early referral increases parental authorization of donation by allowing greater time to consider this option. ${ }^{19,26}$

All patients facing end-of-life issues should be considered possible donors, particularly those presenting with devastating brain injury. Assessment of donor potential should be determined using established guidelines ${ }^{27-30}$ and coordinated with a KDP, or an expert in the area of organ donation. The use of clinical triggers or other methods to facilitate prompt identification of all possible donors, in conjunction with a policy of required referral, will help to improve performance in the process of pediatric donation. ${ }^{24}$ Systematic audit of all potential donors should occur to ensure accountability and responsibility for all providers involved in the donation process. ${ }^{25}$

\section{DETERMINATION OF DEATH}

Deceased donation is conditional upon professional confidence and societal trust in the determination of death and must be supported by a legislative framework. ${ }^{31}$ Public and also professional discomfort or even distrust in the process of determining death in children may undermine support for deceased donation. Factors that may impair opportunities for donation within the hospital setting include: parents' and health professionals' lack of knowledge and understanding of death determination ${ }^{20,26}$; poor communication, including the diversity of terminology used to describe death; and variations in practice for the determination of death. ${ }^{32-35}$

All processes for the determination of pediatric death, whether through neurological or circulatory criteria, should be governed by regional, national, or international guidelines (e.g., $\left.{ }^{36-38}\right)$. Global standardization of practice is desirable; however, there may be variable local requirements for the process of death determination-such as use of specific diagnostic modalities and the timing of repeat evaluations. Policies governing determination of death should identify suitably qualified professionals to determine death and stipulate requirements for the documentation of death. Determination of death should occur in a timely manner, and the process should be carefully explained to parents so there is understanding and confidence in this determination.

\section{ENGAGEMENT WITH FAMILIES}

Parents and families are central to the process of pediatric donation. All families should be provided the opportunity to 
make a decision regarding organ donation whenever this possibility exists. The option of donation should routinely be offered in the context of end-of-life care, with a personalized approach to each case taking into account cultural, religious, and other aspects related to the child and family, and the circumstances of death. ${ }^{19,26}$

Understanding factors that influence parental decisions can increase consent rates for donation. Where decisionmaking occurs, many parents choose to authorize donation. ${ }^{14,18}$ However, research in this area of pediatric donation is limited. Available evidence about approaching parents for pediatric donation reveals differences from adult authorization from a spouse. Although approach for donation by a trained KDP is strongly recommended for adults, evidence suggests that authorization for pediatric donation increases when a competent and trusted person from the healthcare team and a KDP discuss donation opportunities. ${ }^{26}$ An appropriate requestor need not be a clinician, provided they have received suitable training in this field. Preexisting positive attitudes toward organ donation, exposure to information about donation, family consensus, sensitivity of the requestor, sufficient time for decision making, and introduction of the topic of donation by a trusted member of the child's health care team are among the factors which positively influence consent for pediatric donation from families. ${ }^{19,26}$ Approaching families about pediatric donation should be planned with close collaboration between the KDP and the critical care team. Donation is a decision made by the family or surrogate, not the health care team. Medical staff should be prepared to support parents who may initiate conversations about donation. . $^{2,39}$

The experience, expertise, and attitudes of health professionals in the PICU-and in the emergency department where dying children are more rarely situated ${ }^{23}$ - play a critical role in facilitating family decision making about donation and improving the overall experience of families during the death of their child. Effective and ongoing communication with parents must begin early in the process of caring for a critically ill or injured child. Families should be well informed by treating clinicians throughout their time in hospital, with regular, clear, consistent and sensitively conveyed communication, so as to assist in understanding and acceptance of a less than favourable outcome or impending death, futility of interventions where relevant, and the determination and declaration of death. ${ }^{19,23,26}$

Donation discussions should assess and directly address concerns and barriers to donation, including consideration of the preferences of the child when known. ${ }^{22}$ Parents of potential pediatric donors should be informed of the possible allocation of pediatric organs to adult recipients, with reasons for such allocation explained and the overall benefits to children in need of transplantation detailed. ${ }^{3}$ Health care professionals providing end-of-life care should understand that allowing families to pursue donation opportunities may potentially provide solace as parents face the tragic loss of a child. Careful consideration of donation opportunities may minimize the risk of later regret from parents who decline donation. ${ }^{19,26}$

\section{MANAGEMENT OF DONORS}

Where possible, pediatric donors are best managed collaborating with KDP in a pediatric facility by pediatric critical care specialists who understand the unique needs of children and their families. ${ }^{18,40}$ Management of the potential donor should be viewed as a continuum of care. This includes family support throughout the donation process and appropriate comfort measures for potential DCD donors. Continuation of medical management after determination of death if donation is planned is essential to avoid loss of transplantable organs. Medical care after death should be directed toward sustaining organ viability. Specific protocols can preserve opportunities for donation and assist in standardizing donor management. Use of donor management goals increases available organs for transplantation. ${ }^{40-42}$ Protocols and goals should be clearly established using existing national or international resources and guidelines and complemented by educational and training programs for relevant staff. When implemented, consent rates for donation and the number of organs recovered for transplantation increase. ${ }^{43}$

Parental requests (e.g., regarding integration of cultural or religious rituals with organ recovery process) should be honored where possible, and parents should be allowed to be with their child until the time of organ recovery. Organ recovery should be coordinated with surgical recovery teams and operating room staff who participate in the continuum of care. Parental support is essential during and after organ recovery and support should also be available for medical staff after the emotionally taxing event of the death of a child. Donation may comfort not only families, but also the medical team, ${ }^{19,44}$ and donation outcomes should be shared with the family and staff.

\section{ORGAN ALLOCATION}

Allocation of pediatric donor organs is complicated by several factors. Size matching considerations, organ-specific issues, use of various prioritization schemes to optimize utilization of pediatric donor organs, and access to transplantation for pediatric recipients. ${ }^{45-50}$ Allocation decisions may influence public support and parental consent for pediatric donation. ${ }^{19,26,49}$ Accordingly, allocation systems should strive for transparency, so as to avoid for example parental disappointment where organs are unexpectedly allocated to adults, and ensure outcomes of allocation policies meet their underlying goals. Allocation systems, including those prioritizing pediatric recipients, should be carefully evaluated with respect to their impact on pediatric access to organ transplantation and optimal utilization of pediatric donor organs. ${ }^{1,45,49}$

Use of neonatal and smaller pediatric donor organs is increasing. ${ }^{2}$ Opportunities for transplantation of neonatal and pediatric DCD organs into adult or pediatric recipients as clinically appropriate should be maximized. Barriers to the recovery or use of neonatal and pediatric donor organs ${ }^{15,16}$ and transplantation to pediatric recipients (e.g., concerns about adherence, or lack of suitable recipients within national transplant programs) undermine the goals of allocation policies and should be addressed where possible. International collaboration and use of organ sharing agreements may increase the utilization of pediatric organs for transplantation by potentially reducing discard of organs due to the lack of suitable local recipients. ${ }^{48}$ Ongoing research evaluating the use of vascularized composite grafts and downsizing of adult deceased donor organs for pediatric recipients should also continue. Allocation 
TABLE 2.

\section{Core recommendations of the expert working groups}

\section{Priority interventions}

1. Promote public and professional awareness of pediatric deceased donation

- Pediatric specific data to be henceforth included in the Global Observatory on Organ Donation and Transplantation, ${ }^{52}$ to provide a comprehensive account of activities internationally.

2. Improve public and professional understanding and support for donation through education

- Organizations responsible for the public education and promotion of donation are urged to develop and include information specific to pediatric donation;

- The media should be encouraged and assisted to report accurately and sensitively on deceased donation and related events to address myths and misperceptions.

- Professionals responsible for managing critically ill children should routinely receive training in provision of end-of-life care and organ donation (including DCD), as well as death determination;

- Healthcare teams and the KDP or organ recovery specialist should work together to increase chances of successful donation and recovery of pediatric organs;

- Health professionals from all specialties and disciplines (e.g. nurses, physicians, physician assistants and allied health workers including neonatology, palliative care, anaesthesia, emergency medicine) who may be involved with care of potential or actual donors should be encouraged and enabled to access donation education. Additionally, medical examiners and coroners should receive education about donation and work with healthcare teams to preserve the option of donation;

- The Transplantation Society and other professional organizations should support educational and training opportunities at national and international professional meetings;

- National and international professional organizations should assist in development and promotion of educational resources to meet local needs.

3. Expand research in pediatric donation

- Clinical, health policy and social science researchers should be encouraged and supported to undertake

o cross-cultural research investigating attitudes of healthcare providers toward pediatric donation and potential barriers to their participation in donation opportunities, and factors influencing family decision-making in pediatric donation;

o evaluation of the potential for pediatric donation in the context of different health systems, and of factors impeding or facilitating opportunities to establish donation programs;

- For established programs, ongoing evaluation of donation processes, policies and guidelines, including those governing allocation of recovered organs should be performed and outcomes published.

4. Improve access to and implementation of policies and protocols

- Health authorities should strive to develop systems enabling potential pediatric donors to be cared for in pediatric institutions by individuals trained in the unique needs of children and their families;

- Pediatric protocols should be routinely used where possible to standardize pediatric donation and management practices. Health authorities, professional organizations, and healthcare institutions providing care for pediatric patients should collaborate and promptly establish plans for development, introduction and implementation of standardized, best practice guidelines that can be adapted by local health systems. These should include guidelines for:

o recognition of potential donors;

o timely and accurate determination of death;

o provision of care to potential donors and their families;

o optimal management of the donor;

o recovery, allocation, and transplantation of donor organs;

- All policies pertaining to pediatric donation and transplantation should be consistent with the WHO Guiding Principles on Human Cell, Tissue and Organ Transplantation ${ }^{31}$ and the Declaration of Istanbul on Organ Trafficking and Transplant Tourism. ${ }^{53}$

policies should be developed and appropriately revised as these practices evolve (e.g., $\left.{ }^{49,51}\right)$.

\section{CORE RECOMMENDATIONS}

The lack of research evaluating the international scope, quality, and impact of policy and strategic interventions in the field of pediatric donation provides a limited evidence base for recommendations for practice. The consensus of the expert working groups is that increased awareness, education, and development and use of guidelines are requirements for best practice in pediatric donation. Furthermore, research evaluating clinical practices and outcomes thereof, education interventions, and implementation of policy and guidelines will inform development of more specific evidence-based guidelines and recommendations for practice in the future. Table 2 summarizes the core recommendations for immediate intervention by governments, health authorities, institutions and professional organizations seeking to improve pediatric donation. Although this meeting was concerned with pediatric donation of solid organs, we note that many of these recommendations are also applicable to donation of tissue for transplantation.

\section{CONCLUSIONS}

This report of the Transplantation Society Meeting on Pediatric Deceased Donation advocates the routine provision of opportunities for deceased donation by pediatric patients. Recommendations based on available evidence, expert opinion, and consensus highlight the need for multidisciplinary research and dedicated training and education in the field of pediatric deceased donation among the public and health care professionals to preserve and provide the opportunity for donation where possible for children and their families. 
The importance of providing expert holistic care for children and their families throughout the end of life, including donation where relevant, consistent with ethically informed evidence-based and consensus-based guidelines and policies is noted. In particular, the need for consistency and confidence in the determination of death through standardized practice in accordance with regional, national, and international guidelines is noted. The Meeting thus conveys an international call for more clinical, social sciences and health policy research in order to develop and evaluate evidencebased resources needed to inform provision of best practice care in deceased donation for neonates and children.

\section{ACKNOWLEDGMENTS}

Participants in the Geneva Meeting acknowledge the extraordinary gift of all pediatric donors and their families.

The Geneva Meeting was convened by the Ethics Committee of The Transplantation Society. We are appreciative of participation by representatives of the World Health Organization. We wish to thank Genevieve Leclerc of The Transplantation Society for her administrative support of the meeting.

\section{REFERENCES}

1. American Academy of Pediatrics. Committee on Hospital Care, Section on Surgery, Section on Critical Care. Pediatric organ donation and transplantation. Pediatrics. 2010;125:822.

2. Siebelink MJ, Albers MJ, Roodbol PF, et al. Key factors in paediatric organ and tissue donation: an overview of literature in a chronological working model. Transpl Intl. 2012;25:265.

3. Workman JK, Myrick CW, Meyers RL, et al. Pediatric organ donation and transplantation. Pediatrics. 2013;131:e1723.

4. Organ Procurement and Transplantation Network. Death removals of candidates by age by year. Based on OPTN data as of November 1, 2014. Available at: http://optn.transplant.hrsa.gov/converge/LatestData/ rptData.asp. Accessed November 6, 2014.

5. NHS Blood and Transplant. Deaths on the UK paediatric transplant list, 1 April 2004 to 31 March 2014, by organ and year.

6. Organ Procurement and Transplantation Network. Donors Recovered in the U.S. by Donor Age Type for the year 2013, Based on OPTN data as of June 6, 2014. Available at: http://optn.transplant.hrsa.gov/latestData/ rptData.asp Accessed June 14, 2014.

7. Australia and New Zealand Organ Donation Registry. Annual Report 2013, Chapter 4, Donor Profile. p. 4-2. Available at: http://www.anzdata.org.au/ anzod/ANZODReport/2013/2013ANZOD_annrpt_04_donorprofile_v0.6. pdf. Accessed October 21, 2014.

8. NHS Blood and Transplant. Activity Report 2012-2013, Section 3 - Organ Donation Activity. 2013. Available at: http://www.organdonation.nhs.uk/ statistics/transplant_activity_report/current_activity_reports/ukt/organ_ donation_activity.pdf, p.13 Accessed October 21, 2014

9. de la Rosa G, Ramón S, Domínguez-Gil B, et al. Potential pool of paediatric donors in Spain. Unpublished paper presented at European Society for Organ Transplantation conference in Vienna, September 2013.

10. Rahmel A. Eurotransplant Annual Report 2013. Available at: https://www. eurotransplant.org/cms/mediaobject.php?file=AR20135.pdf. Accessed November 2, 2014.

11. Organ Procurement and Transplantation Network. Waitlist: Age Type by Candidates, Current U.S Waiting List. Based on OPTN data as of October 24, 2014 Available at: http://optn.transplant.hrsa.gov/converge/latestData/ rptData.asp. Accessed November 2, 2014.

12. NHS Blood and Transplant. Organ Donation and Transplantation activity figures for the UK as at 12 April 2013. Available at: http://www. organdonation.nhs.uk/statistics/downloads/annual_stats.pdf. Accessed: October 21, 2014.

13. From waitlist data published by Transplant Australia. How the waiting lists operate. 2009. Available at: http://www.transplant.org.au/IgnitionSuite/ uploads/docs/waiting_list.pdf. Accessed: October 21, 2014.

14. Siebelink MJ, Albers MJ, Roodbol PF, et al. Children as donors: a national study to assess procurement of organs and tissues in pediatric intensive care units. Transpl Int. 2012;25:1268.
15. Charles E, Scales A, Brierley J. The potential for neonatal organ donation in a children's hospital. Arch Dis Child Fetal Neonatal Ed. 2014;99:F225.

16. Hanley H, Kim S, Willey E, et al. Identifying potential kidney donors among newborns undergoing circulatory determination of death. Pediatrics. 2014;133:e82.

17. Labrecque M, Parad R, Gupta M, et al. Donation after cardiac death: the potential contribution of an infant organ donor population. J Pediatr. 2011;158:31

18. Webster PA, Markham L. Pediatric organ donation: a national survey examining consent rates and characteristics of donor hospitals. Pediatr Crit Care Med. 2009;10:500.

19. Hoover SM, Bratton SL, Roach E, et al. Parental experiences and recommendations in donation after circulatory determination of death. Pediatr Crit Care Med. 2014;15:105.

20. Curley MA, Harrison $\mathrm{CH}$, Craig $\mathrm{N}$, et al. Pediatric staff perspectives on organ donation after cardiac death in children. Pediatr Crit Care Med. 2007;8:212.

21. Bellali T, Papadatou D. The decision-making process of parents regarding organ donation of their brain dead child: a Greek study. Soc Sci Med. 2007;64:439.

22. Siebelink MJ, Geerts EA, Albers MJ, et al. Children's opinions about organ donation: a first step to assent? Eur J Public Health. 2012;22:529.

23. O'Malley P, Barata I, Snow S, et al. Death of a child in the emergency department. Pediatrics. 2014;134:e313.

24. Shafer TJ, Wagner D, Chessare J, et al. US organ donation breakthrough collaborative increases organ donation. Crit Care Nurs. 2006;26:33.

25. De la Rosa G, Domínguez-Gil B, Matesanz R, et al. Continuously evaluating performance in deceased donation: the Spanish quality assurance program. Am J Transplant. 2012;12:2507.

26. Rodrigue JR, Cornell DL, Howard RJ. Pediatric organ donation: what factors most influence parents' donation decisions? Pediatr Crit Care Med. 2008:9:180.

27. Domínguez-Gil B, Delmonico FL, Shaheen F, et al. The critical pathway for deceased donation: reportable uniformity in the approach to deceased donation. Transpl Int. 2011;24:373

28. UNOS. Critical Pathway for the Pediatric Organ Donor. Available at: http:// transplantpro.org/wp-content/uploads/Critical_Pathway_Pediatric.pdf. Accessed October 21, 2014.

29. NHS Blood and Transplant. Assessment for Donation after Brain-stem Death, Children Available at: http://organdonor.mapofmedicine.com evidence/nhsbt/donation_after_brain_stem_death_children1.pdf. Accessed October 21, 2014.

30. NHS Blood and Transplant. Donation after Circulatory Death, ChildrenAssessment. Available at: http://eng.mapofmedicine.com/evidence/map/ donation_after_circulatory_death_children1.html. Accessed October 21, 2014.

31. World Health Organization. WHO guiding principles on human cell, tissue and organ transplantation. Transplantation. 2010;90:229.

32. Mathur M, Petersen L, Stadtler M, et al. Variability in pediatric brain death determination and documentation in southern California. Pediatrics. 2008;121:988.

33. Joffe AR, Shemie SD, Farrell C, et al. Brain death in Canadian PICUs: demographics, timing, and irreversibility. Pediatr Crit Care Med. 2013;14:1.

34. Lustbader D, O'Hara D, Wijdicks EF, et al. Second brain death examination may negatively affect organ donation. Neurology. 2011;76:119.

35. Rhee JY, Ruthazer R, O'Connor $\mathrm{K}$, et al. The impact of variation in donation after cardiac death policies among donor hospitals: a regional analysis. Am J Transplant. 2011;11:1719.

36. Nakagawa TA, Ashwal SA, Mathur M, et al., and the Committee for Brain Death in Infants and Children. Guidelines for the determination of brain death in infants and children. An update of the 1987 task force recommendations. From the Pediatric Section of SCCM, American Academy of Pediatrics, Child Neurology Society. Crit Care Med. 2011;39:2139.

37. American Academy of Pediatrics. Committee on Bioethics. Policy Statement Ethical Controversies in Organ Donation After Circulatory Death. Pediatrics. 2013:131:1021.

38. Shemie SD, Doig C, Dickens B, et al. Severe brain injury to neurological determination of death: Canadian forum recommendations. Can Med Assoc J. 2006;174:S1

39. Naim MY, Hoehn KS, Hasz RD, et al. The Children's Hospital of Philadelphia's experience with donation after cardiac death. Crit Care Med. 2008;36:1729.

40. Nakagawa TA, Mou SS. The Process of Organ Donation and Donor Management. In: Furhman BP, ed. Pediatric Critical Care. 4th ed. Philadelphia, PA: Elsevier Mosby; 2011. 
41. Mallory GB Jr, Schecter MG, Elidemir O. Management of the pediatric organ donor to optimize lung donation. Pediatr Pulmonol. 2009; 44:536.

42. Malinoski DJ, Patel MS, Daly MC, et al. The impact of meeting donor management goals on the number of organs transplanted per donor: results from the United Network for Organ Sharing region 5 prospective donor management goals study. Crit Care Med. 2012;40:2773.

43. Nakagawa TA. The Current State of Pediatric Donation: Organ Procurement Transplantation Network (OPTN) Data 2011-2012. Presented at the National Pediatric Summit in Fort Worth, Texas. 2013.

44. Merchant SJ, Yoshida EM, Lee TK, et al. Exploring the psychological effect of deceased organ donation on the families of organ donors. Clin Transplant. 2008;22:341

45. Agarwal S, Oak N, Siddique J, et al. Changes in pediatric renal transplantation after implementation of the revised deceased donor kidney allocation policy. Am J Transplant. 2009:9:1237.

46. Almond CS, Thiagarajan RR, Piercey GE, et al. Waiting list mortality among children listed for heart transplantation in the United States. Circulation. 2009;119:717.
47. Giovanelli M, Gupte GL, McKiernan P, et al. Impact of change in the United Kingdom pediatric donor organ allocation policy for intestinal transplantation. Transplantation. 2009;87:1695

48. Smits JM, Thul J, Pauw M, et al. Pediatric heart allocation and transplantation in Eurotransplant. Transpl Int. 2014;27:917.

49. Sweet SC, Barr ML. Pediatric lung allocation: the rest of the story. Am J Transplant. 2014;14:11.

50. Harambat J, Van Stralen KJ, Schaefer F, et al. Disparities in policies, practices and rates of pediatric kidney transplantation in Europe. $\mathrm{Am} \mathrm{J}$ Transplant. 2013;13:2066.

51. Kaplan K. Kids to get hand transplants at Boston Children's Hospital. Los Angeles Times. 2013. Available at: http://articles.latimes.com/2013/ jun/17/science/la-sci-sn-hand-transplant-boston-childrens-20130617. Accessed October 21, 2014.

52. The Global Observatory on Organ Donation and Transplantation. Available at: http://www.transplant-observatory.org/ Accessed: October 21, 2014.

53. Steering Committee of the Istanbul Summit. Organ trafficking and transplant tourism and commercialism: the Declaration of Istanbul. Lancet. 2008;372:5.

LWW authors can order up to $500 \mathrm{cop}$
articles at a special rate. In addition
article ePrints are also available.
LWW Article Reprints are:

- Professional, high-quality documents

- Printed on premium paper

- Inclusive of images, charts, graphs, and graphics

- Available with covers (optional)

\section{Order today!}

To place your order, visit www.LWWonline.com/reprints or call 1-866-903-6951.

\section{Q Lippincott Williams \& Wilkins} a Wolters Kluwer business 